\title{
Relationship between moth (night active Lepidoptera) diversity and vegetation characteristics in southern Sweden
}

\author{
Torbjörn Tyler $^{1} \mathbb{0}$
}

Received: 19 March 2020 / Accepted: 29 August 2020 / Published online: 6 October 2020

(c) The Author(s) 2020

\begin{abstract}
The diversity and community composition of moths (both macro- and micromoths) at 32 sites, representing a wide range of habitat types (forests, grasslands, wetlands, agricultural and urban areas) within a restricted region in central Scania, southern-most Sweden, was investigated by use of light moth traps and compared with vascular plant species richness and habitat characteristics. The results revealed a highly significant general association between vegetation composition and the composition of the moth community and multivariate (CCA) analyses indicated light availability and soil fertility parameters ( $\mathrm{pH}$ and macronutrients) to be the habitat characteristics that best correlated with moth community composition. Less strong, but still significant, positive relationships between moth abundance and local vascular plant diversity were also revealed. Moth species richness was positively correlated with diversity of woody plant genera in the neighborhood, but not with local vascular plant diversity in general. As for more general site characteristics, there were tendencies for higher moth richness and abundance at sites with more productive soils (well-drained, high $\mathrm{pH}$, high nutrient availability), while shading/tree canopy cover, management, soil disturbance regimes and nectar production appeared unrelated to moth community parameters. It is concluded that local moth assemblages are strongly influenced by site characteristics and vegetation composition. Implications for insect conservation: The results show that obtaining moth data on a local scale is useful for conservation planning and does not need to be very cumbersome. Local moth assemblages monitored are indeed related to local site characteristics of conservation relevance.
\end{abstract}

Keywords Conservation $\cdot$ Macrolepidoptera $\cdot$ Microlepidoptera $\cdot$ Light trap $\cdot$ Species diversity $\cdot$ Vegetation

\section{Introduction}

Various groups of night active Lepidoptera (members of e.g. Geometroidea, Noctuoidea, Bombycoidea, Tortricoidea, Pyraloidea, Yponomeutoidea and Gelechioidea) constitute a significant part of the biodiversity in many regions of the world. Furthermore, these insects have several ecologically important roles, as herbivores and as a food resource for other insects, birds and bats (Vaughan 1997), and some of them are important as pollinators of particular plant species (e.g. some Orchids and many members of Caryophyllaceae). However, moths are rarely considered in conservation assessments (Lintott et al. 2014; Ballesteros-Mejia et al. 2017). In Sweden, conservation assessments of grassland

Torbjörn Tyler

torbjorn.tyler@biol.lu.se

1 The Biological Museum, Department of Biology, Lund University, Box 117, 22100 Lund, Sweden habitats are generally based on vascular plants, sometimes with the addition of some in comparison species-poor insect groups such as bees and butterflies and forest assessments are mostly based on cryptogams. However, in both habitat types, and in particular in temperate forests, moths are richly represented, take part in vital ecological processes (Truxa and Fiedler 2012a; Infusino and Scalerico 2018; Merckx et al. 2019) and deserve more conservation attention (Ballesteros-Mejia et al. 2017). This in particular since there are indications that moth diversity may accurately reflect conservation values (Uhl et al. 2016; Zou et al. 2016).

The recent startling decline in insect population densities in many regions (e.g. Sorg et al. 2013) calls for an increased awareness of these organisms, but the ecology of many moth species is still very incompletely known. In particular, this goes for the night-active insects including Lepidoptera (Franzén and Johannesson 2007; Groenendijk and Ellis 2011). Our knowledge about the host plants for the larval stages of many moths are strongly biased towards cultivated, 
economically important and easy-to-observe plant species and even less is known about the habitat requirements and habits of the adult moths (Franzén and Johannesson 2007). While there are quite some recent studies of relationships between moth diversity and environmental gradients or characteristics in tropical and Mediterranean habitats (e.g. Axmacher et al. 2004, 2009; Beck et al. 2011; Uhl et al. 2016; Merckx et al. 2019), there are only few such studies in temperate or boreal landscapes (e.g. Littlewood 2008; Highland et al. 2013; Horvath et al. 2016; Zou et al. 2016) and hardly any from the Nordic region.

A major reason for this apparent lack of ecological knowledge about moths probably is that these night active organisms have been difficult to study in the past, in particular at a local scale. It is well known since long that most moth species are attracted to light of particular wavelengths, but electricity supply and fragile and weather-sensitive bulbs have traditionally been needed to produce such light, thereby restricting its use to sites with some infrastructure. Furthermore, with the intention to be able to catch as many moths as possible per time unit, bulbs emitting very strong light have traditionally been used, attracting moths from relatively large distances and thus not only those inhabiting the local habitat. However, over the last 2-3 decades, low-wattage LEDs or tube lights producing actinic or UV light and readily powered by relatively small batteries have become available. Such simple low-weight light traps are ideal for studies of local moth populations also in remote areas (Jonason et al. 2014; Merckx and Slade 2014) and have enabled multiple recent studies where the local moth communities at numerous sites are compared (e.g. Axmacher et al. 2004, 2009; Merckx et al. 2012; Uhl et al. 2016). Their ability to selectively attract and catch moths active at a very local scale (within 10-20 m) is particularly promising for studies of relationships between moth communities and local environmental conditions or vegetation characteristics (Truxa and Fiedler 2012b), although differences among species and higher taxa in how well they are represented in light-trap catches needs to be considered (Merckx and Slade 2014).

On a more general scale, it has been much debated to what extent diversity of different organismal groups correlate (Gaston 1996; Rodrigues and Brooks 2007; Brunbjerg et al. 2018). From a conservation perspective it would be most useful if diversity of some easily observable groups of organisms, such as vascular plants, birds or butterflies, could be used as proxies for overall species richness at a local scale, but multiple studies have demonstrated that such ideas may generally be deemed as wishful thinking (reviewed by Rodrigues and Brooks 2007), although an approach using a combination of vascular plant species diversity and other habitat characteristics that may be inferred from the speciesspecific traits of the plant species present appear promising (Brunbjerg et al. 2018). Still, if not for other reasons, since the larval stages of most moth species are dependent on one or a few particular plant species, moths ought to be dependent on particular habitats and vegetation types and increasing plant species richness should allow for an increase in the number of species of moth larva that may be sustained. However, moths are mobile organisms and their life cycles are rather complex such that it may be suspected that the needs and preferences of e.g. the adult moths may be rather different from those of the larval stages of the same species. Thus, it is in no way self-evident that habitats with a species-rich vegetation, potentially providing food for a great diversity of moth larva, house the most rich or diverse communities of adult flying moths (Axmacher et al. 2009).

The aim of the present study was to investigate the local communities of night active adult moths of a wide variety of habitats within a restricted region in Sweden and compare it with local plant diversity and vegetation characteristics to provide basic information relevant for conservation assessments and evaluate the importance of moths in such contexts. More precisely, I wanted not only to compare the moth species diversity of the different major habitat types dominating in the region, but also to test if the abundance and/or species diversity of moths at a local scale is correlated with vascular plant diversity and/or any more general habitat characteristics that may be deduced from vegetation composition, e.g. tree canopy cover/shading, soil nutrient levels or estimates of nectar production.

\section{Materials and methods}

\section{Study sites}

Thirty-two sites around Höör municipality in central Sca-

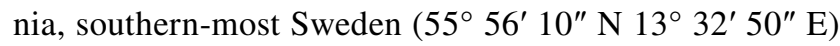
were selected for the study ( 26 sites within $10 \mathrm{~km}$ from the municipality and 6 sites ca $16 \mathrm{~km}$ further to the north). All sites were at least $200 \mathrm{~m}$ apart (mean distance between pairs of sites $7.3 \mathrm{~km}$, range $0.2-19 \mathrm{~km}$ ). The sites were selected to represent as much as possible of the variation in vegetation found in the region, which is a rather small-scale mosaic of agricultural land, different types of both deciduous and coniferous forest, and built-up areas. Thus, gardens/parks (4 sites), industrial areas (2), semi-natural pastures/meadows (7), deciduous forest (7), coniferous forest (2), bogs/swamp forest (5) and ecotones in the agricultural landscape (5) were all represented (Fig. 1). As far as possible, the samples were collected from the center of a relatively large $(\approx 1$ ha) landscape element with homogeneous vegetation and land use.

The basic climatic conditions of the region are (open data from the Swedish metrological and hydrological institute): Mean annual temperature $+6.8^{\circ} \mathrm{C}$, mean temperature of warmest month $+16^{\circ} \mathrm{C}$, mean temperature of coldest month 
Fig. 1 Photos of some of the sites were moths were trapped, illustrating the diversity of the habitats studied. The moth trapping equipment used throughout the study is seen in the lower right photo
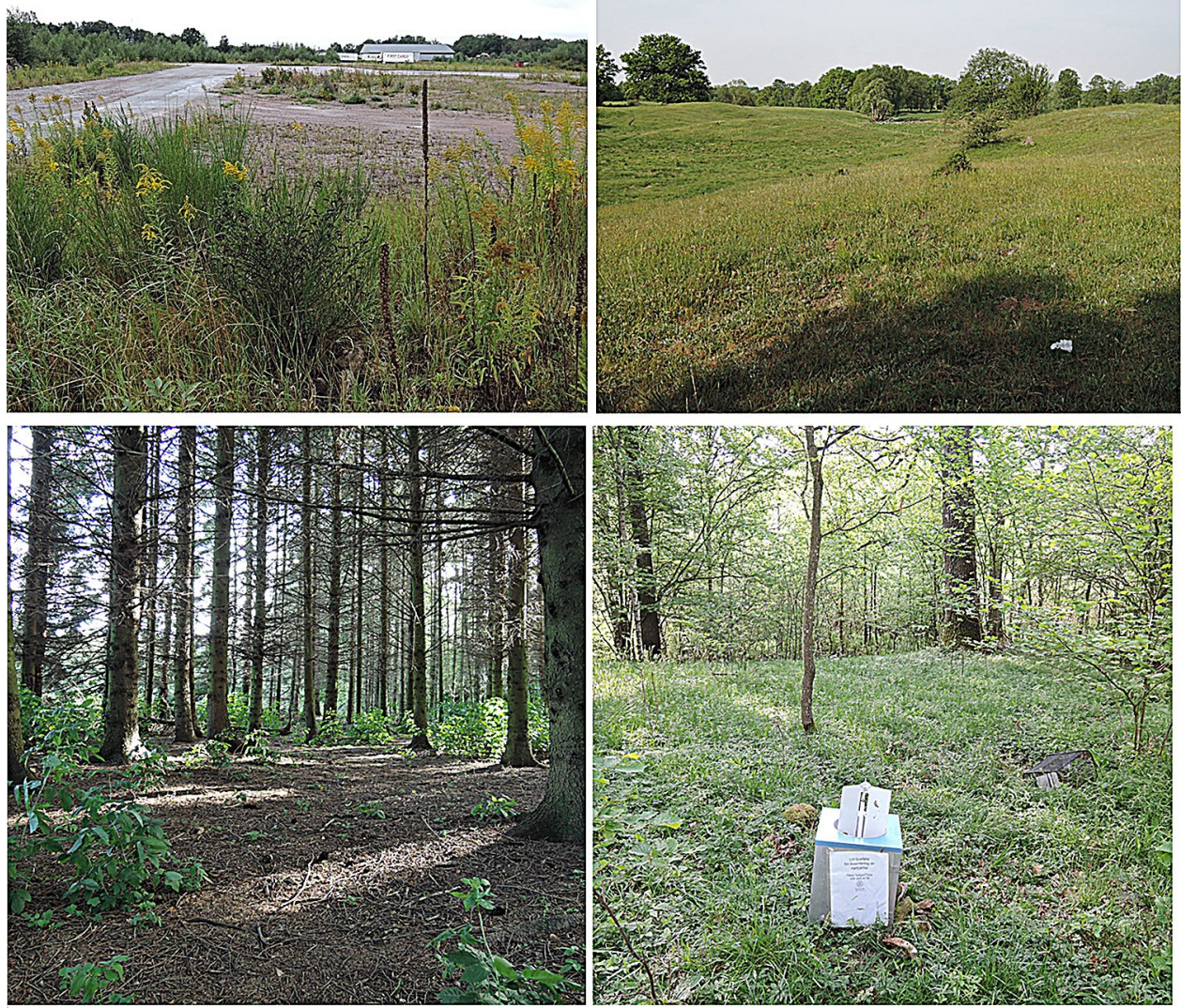

$-1{ }^{\circ} \mathrm{C}$, vegetation period 205 days, mean annual precipitation ca $750 \mathrm{~mm}$.

\section{Moth data}

The moth data was collected 2015-2018. At each study site, a battery-powered 'Heath trap' with a $6 \mathrm{~W}$ actinic light tube (Watkins and Doncaster model E7585) and filled with cardboard egg-boxes (to provide shelter and keep the moths immobile) was put at least one night every month from April to November (8-17 nights per site with a mean of 9.2 nights per site giving a total of 295 trap nights). Typically, three traps/sites were sampled each night. To avoid systematic biases the night-trap combinations differed between months, but for logistic reasons a fully randomized sampling scheme was not feasible. Whenever possible, nights early in the moon phase (i.e. with no distracting moon light) were chosen, but otherwise no discrimination between nights (e.g. based on weather conditions) were made. The traps were put out before dusk and emptied the following morning when all moth individuals were photographed. The moths on the photographs were then identified to the lowest taxonomic level possible based on photos alone (548 individual species +5 pairs of cryptic species + the genera Amphipoea (4 spp.), Mesapamea (2 spp.), Cnephasia (7 spp.) and Neofaculta (2 spp.) whose species had to be treated collectively), using standard web-resources (mostly www.vilkenart.se) and with frequent help from the Facebook community of Swedishspeaking moth enthusiasts.

To compensate for slight differences between sites in terms of sampling effort, the data were standardized before any analyses by averaging across the 7 months (March \& April and October \& November were lumped) and averaging across nights in those cases when data from more than one night the same month had been collected. Both the number of moth species and the number of moth individuals, and their combination in the form of various diversity statistics, were calculated per site per months and used in subsequent analyses.

All basic observation data, including photos of the moths, have been submitted to the Swedish Species Gateway and are freely available from there. 


\section{Vegetation data}

Two sets of vegetation data were collected: (1) a list of all species of vascular plants present in the vegetation within a radius of $5 \mathrm{~m}$ from the trap, and (2) a list of all woody plants within ca $50 \mathrm{~m}$ (i.e. within sight) from the trap. Many more moth species are known to feed on trees and shrubs than on individual herb species and moths feeding in large and tall trees may be suspected to move longer distances than those appearing from herbs near the ground motivating a larger sampling area for these. For example, while most individual herbaceous species are known to act as hosts for only a handful moth species, no less than 267 species of moths known from Scania have been documented to feed on oaks, Quercus (data extracted from the web resource www.vilkenart.se). For all subsequent analyses except the one based on ecological plant indicator values described below, the species lists were reduced to lists of plant genera since most moth species feed on multiple, but usually related, plant species and do commonly not discriminate between closely related plant species of the same genus. In addition, the percentage of the heavens (everything above the horizon) covered by tree canopy at each site was estimated visually.

Based on the plant species lists and plant ecological indicator values (Tyler et al. 2020, largely the same as those previously used by Tyler et al. 2018), the following ecological characteristics of the study sites were also estimated: nectar production, light/shade, soil moisture, soil $\mathrm{pH}$, soil Nitrogen, soil Phosphorus, influence of management (grazing/mowing) and soil disturbance.

\section{Statistical analyses}

First, to check for any autocorrelation among sites in the data (resulting from spatial patterns or from that sites were sampled in a non-random order), a Mantel test was performed between inter-site distance matrices based on the moth data and inter-site geographic distances.

Then, to evaluate the relationships between similarities/ differences in the plant and moth communities among sites, Mantel tests were performed between inter-site distance matrices based on the plant and moth data and a variety of distance indices (Bray-Curtis, Dice, Jaccard and Euclidean) that variously account for the abundance (number of individuals caught) of the communities or uses presence/ absence data only.

To further understand the relationship between vegetation composition, presumed to largely reflect ecological site characteristics, and the composition of the moth assemblages, a Canonical Correspondence Analysis (CCA) using 8 site characteristics estimated from the ecological indicator values of the plant species present (nectar production, light/ shade, soil moisture, soil pH, soil Nitrogen, soil Phosphorus, influence of management (grazing/mowing) and soil disturbance) as explanatory variables and the number of individuals per moth species caught as the response variables was performed. Across species means along the two first CCA-axes were computed for Noctuideae (147 species) and Geometridae (134 species) to highlight differences between these dominating taxonomic groups.

To obtain a somewhat more detailed understanding of how the abundance of the most common individual moth species (the 93 species represented in the data by more than 20 caught individuals) relate to habitat characteristics, the relationship between the relative abundance in the local community (proportion of all moth individuals caught at the site that belong to the species concerned), the tree canopy cover, and the eight ecological site characteristics derived from the plant ecological indicator values (means over plant species in the vegetation) was analyzed by Pearson correlation analyses.

To assess relationships with moth diversity, the number of moth individuals caught and the number of moth taxa recorded per night each of the 8 months (averaged across nights when there were data from more than one night the same month) was calculated for each site. In addition, the Shannon diversity index suggested by Fiedler and Truxa (2012) to be the best statistic for summarizing diversity in species-rich incompletely sampled communities of highly mobile insects was calculated for each site. The relationship between these three moth diversity/richness measures and the number of plant genera and woody plant genera in the surrounding vegetation, the tree canopy cover, and the ecological site characteristics derived from the plant ecological indicator values (means over plant species in the vegetation) was analyzed by Pearson correlation analyses.

All statistical calculations were performed in PAST v. 3.24 for Mac (released April 2019, Hammer et al. 2001). Statistical $\mathrm{p}$ values are reported as uncorrected for multiple testing, but results significant also after Bonferroni correction for multiple testing (considering each species or diversity index as one hypothesis) are highlighted in the Results.

\section{Results}

\section{Biodiversity estimates and species abunances}

The number of vascular plant genera within $5 \mathrm{~m}$ distance from the trapping site ranged between 7 and 90 with a mean of 35.5 , and the number of woody plant genera within sight from the trap ranged between 3 and 25 with a mean of 10.7 with the lowest and highest plant diversity observed in a beech forest on acid soil and in a partially wooded meadow, respectively. Percentage tree canopy cover ranged from 10 to $90 \%$ with a mean of $54 \%$. 
The number of moths caught varied strongly over the season, with means of 3-4 individuals per night and trap in March-April and October-November, to 17-18 in June and August, and 23 in July. A total of 7389 moths were caught and identified as belonging to 557 different taxa (548 species, 5 pairs of cryptic species and 4 genera whose species could not be separated). Before correcting for differences in sampling effort, at individual sites, the total number of moth taxa caught ranged from 31 to 127 (mean 85.5) with the lowest species richness in a Betula pubescens swamp forest on acid peat (overgrown former peat pit) and the highest diversity in a Alnus glutinosa swamp forest (Fig. 2). When standardized to one sample per calendar month, the number of moth individuals per night ranged from 3.14 to 21.9 (mean 11.4) and the number of moth taxa per night ranged from 3.12 to 19.5 (mean 9.6) and both moth abundance and species richness per night was lowest at a site in a recently clear-cut former spruce monoculture and highest in a moist and herb-rich mixed deciduous forest along a brooklet, respectively (Fig. 3). The Shannon diversity index ranged from 3.026 to 4.488 with the lowest and highest values at the same sites as for the number of moth individuals and taxa.

The by far most common moth species was Noctua pronuba with 526 caught individuals. The other ten most common species, all with 100-200 caught individuals, were (in descending order): Eilema lurideolum, Luperina testacea, Xestia xanthographa, Mythimna impura, Cerapteryx graminis, Diarsia rubi/florida, Eudonia truncicolella, Pelosia muscerda, Orthosia gothica, Xestia sexstrigata and Diarsia mendica.

\section{Relationship between moth and plant community composition and site characteristics}

The Mantel tests between inter-site distance matrices based on moth community composition and inter-site geographic distances were insignificant $(\mathrm{R} \approx 0.03, \mathrm{p} \approx 0.4$ ), suggesting that there was no spatial autocorrelation (or autocorrelation
Fig. 2 Photos showing the vegetation of the sites were the highest (left) and lowest (right) total number of moth species were recorded
Fig. 3 Photos showing the vegetation of the sites were the highest (left) and lowest (right) moth abundance, number of moth species per trapping nigh and Shannon diversity were recorded
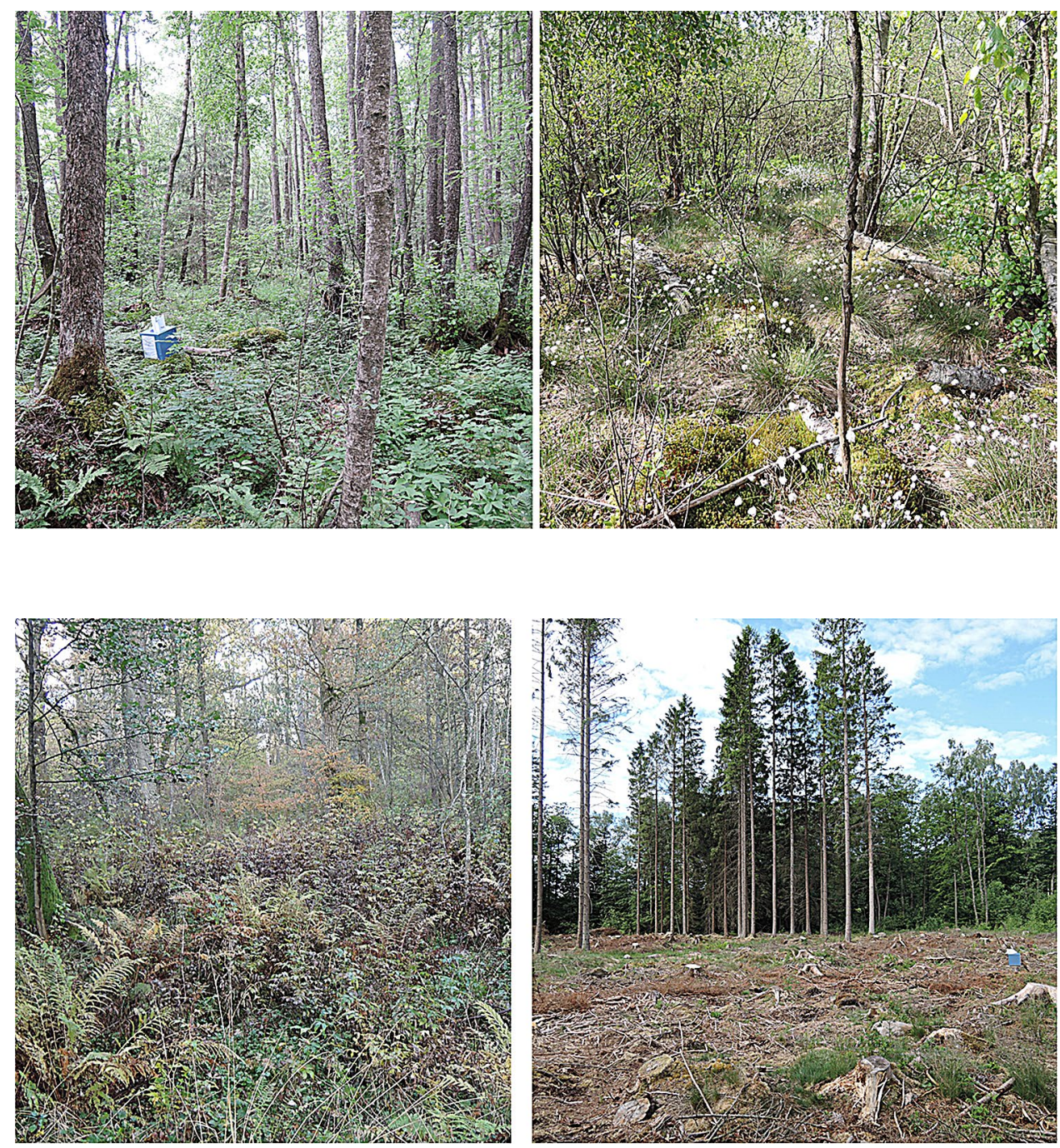
due to that sites were not randomized among trapping nights) in the data that could bias subsequent analyses.

The Mantel tests between inter-site distance matrices based on the plant and moth community composition were on the other hand all highly significant with $\mathrm{p}$ values ranging from $<0.0001$ to 0.025 depending on the combination of distance indices used.

The CCA analysis indicated light availability and soil fertility parameters ( $\mathrm{pH}$, Nitrogen and Phosphorus availability) to be the most influential site variables, while estimated nectar production, disturbance, management and moisture were more weakly correlated with the composition of the local moth assemblage (Fig. 4). As indicated by Fig. 4, the different soil chemistry parameters tended to shape the moth community in much of the same way, and so did light penetration, soil disturbance and nectar production, while habitat management and wetness each represented different independent gradients and the individual moth species are positioned along these combined gradients as shown in Fig. 5. On average, species of Noctuidae were positioned on the negative side of the first CCA-axis (mean - 0.21) while species of Geometridae tended to the positive side (mean 0.46), suggesting that the former prefer more open and nutrient-rich habitats.

\section{Relationship between individual moth species abundance and site characteristics}

Of the 93 common-most moth species whose relative abundance in the local moth communities of individual trapping sites was analysed for relationships with eight ecological site characteristics deduced from the vegetation composition, about half $(42)$ showed significant $(\mathrm{p}<0.05)$ correlations with one or more ecological variable. After Bonferroni correction for multiple tests, 16 of these remained significant and these are marked with an asterisk $(*)$ in the species lists given below.

The highest number of significant relationships was found with light availability and tree canopy cover (21 and 18 relationships, respectively), and as may be expected, the direction of these two relationships generally was similar among species. Thus, species significantly relatively more abundant at sites with high light availability and/or low tree canopy cover included Agrotis exclamationis, Arctia caja, Chrysoteuchia culmella*, Crambus perellus, Eilema lutarellum, Mythimna conigera, Udea lutealis*, Xestia c-nigrum, and $X$. triangulum, while species associated with high tree canopy cover and/or vegetation indicating low light penetration included Agriops marginaria*, Alcis repandata*, Ecliptoptera silaceata*, Ectropis crepuscularia, Epirrita dilutata, Eudonia truncicolella*, Hypomecis punctinalis*, Ochropacha duplaris, Phalera bucephala*, Pheosia gnoma and Ptilodon capucina.

Slightly fewer moth species showed significant associations with Phosporus and Nitrogen availability (17 and 11 , respectively) and these parameters generally showed the same patterns although correlations with Phosporus were generally stronger. Thus, the relative abundance of Arctia caja, Crambus perlellus, Diarsia rubi/florida*, Hydraecia micacea, Mythimna conigera, M. impura*, Tholera decimalis, Udea lutealis and Xestia xanthographa increased with increasing nutrient availability, while the relative abundance of Achlya flavicornis, Agriopis marginaria, Anacampsis blattariella*, Charanyca ferruginea,
Fig. 4 Ordination plot from a Canonical Correspondence analysis of moth trapping sites using 8 site characteristics estimated from the ecological indicator values of the plant species present (nectar production, light/shade, soil moisture, soil pH, soil Nitrogen, soil Phosphorus, influence of management (grazing/mowing) and soil disturbance) as explanatory variables and the number of individuals per moth species caught as the response variables. The eigenvalues/percentages explained by the two first CCA Axes are 0.30/23\% and $0.25 / 19 \%$, respectively

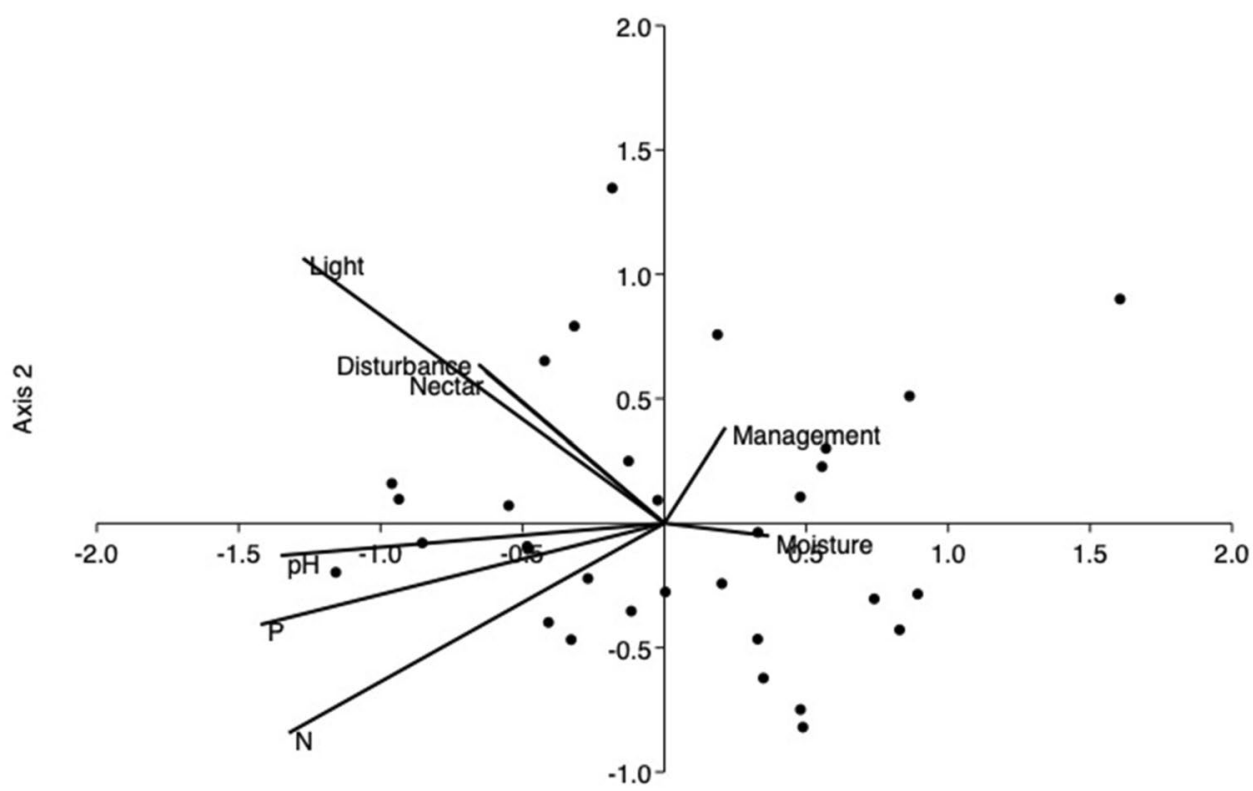

Axis 1 


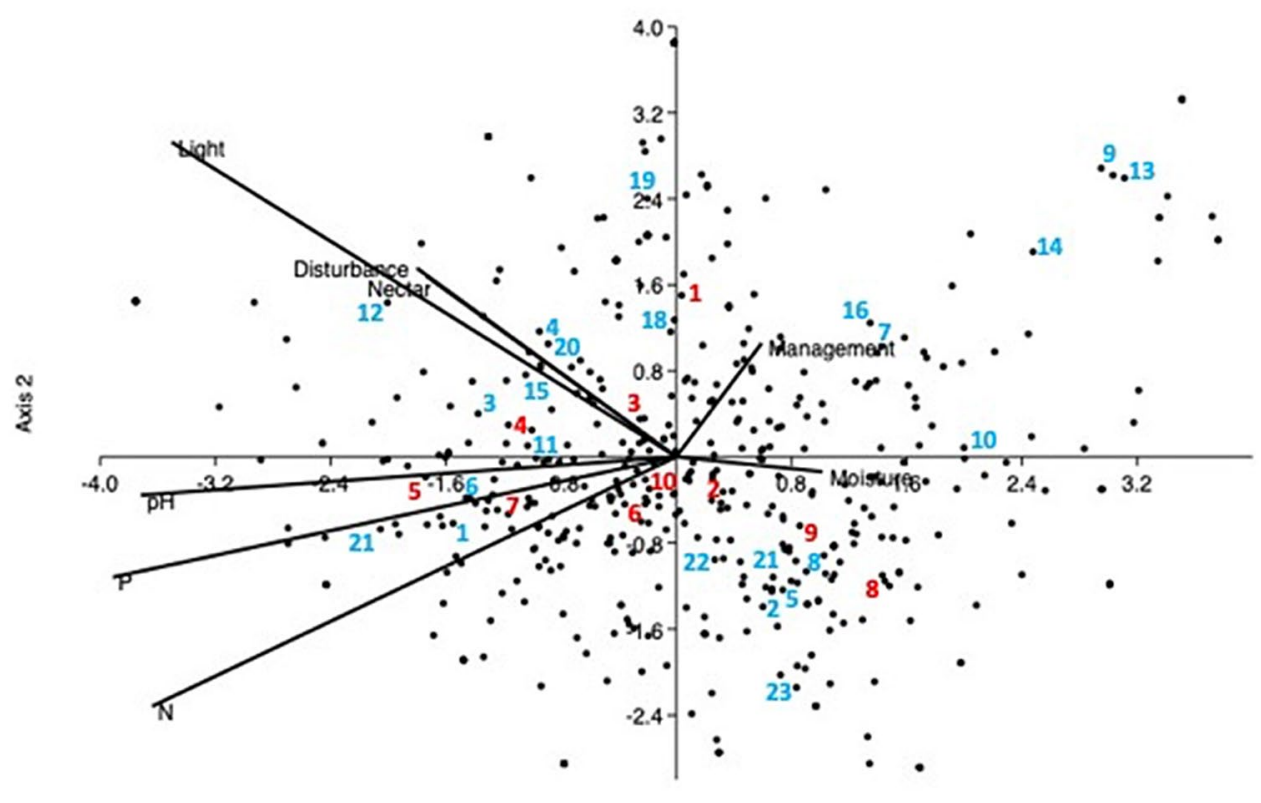

Axis 1

Fig. 5 Same as Fig. 4 but with the position of the moth species indicated. The most common species in the sample are denoted by numbers in red: 1 Noctua pronuba, 2 Eilema lurideolum, 3 Luperina testacea, 4 Xestia xanthographa, 5 Mythimna impura, 6 Cerapteryx graminis, 7 Diarisa rubi/florida, 8 Eudonia truncicolella, 9 Pelosia muscerda, 10 Orthosia gothica. Some other common species with significant associations with the environmental variables (see text) are denoted by figures in blue: 1 Mythimna conigera, 2 Phalera bucephala, 3 Chrysoteuchia culmella, 4 Xestia c-nigrum, 5 Alcis repandata, 6 Crambus perellus, 7 Eulithis testacea, 8 Hypomecis punctinalis, 9 Achlya flavicornis, 10 Agriopis marginaria, 11 Arctia caja, 12 Udea lutealis, 13 Hypenodes humidalis, 14 Anacampsis blattariella, 15 Xestia triangulum, 16 Eulithis populata, 18 Eilema lutarellum, 19 Noctua comes, 20 Agrotis exclamationis, 21 Tholera decimalis, 21 Ecliptoptera silaceata, 22 Epirrita dilutata, 23 Ectropis crepuscularia
Eudonia truncicolella, Eulithis populata, E. testata and Hypenodes humidalis* showed the opposite pattern. Some (8) of these same species also showed significant associations with soil $\mathrm{pH}$ as deduced from the vegetation composition: Diarsia rubi/florida, Mythimna impura increased in relative abundance with increasing soil $\mathrm{pH}$, while Achlya flavicornis, Agriopis marginaria, Anacampsis blattariella*, Eudonia truncicolella, Hypenodes humidalis* $^{*}$ were negatively correlated to soil $\mathrm{pH}$.

Nine species showed significant associations with soil disturbance indicators: Luperina testacea, Noctua comes, Orthosia cerasi*, O. gothica and Udea lutealis* increased in abundance with increasing soil disturbance indicators, while Agriopis marginaria, Eudonia truncicolella, Hydriomena furcata and Ochropacha duplaris showed the opposite pattern.

Five species showed significant responses to habitat wetness with Anacampsis blattariella, Hydriomena furcata, Ochropacha duplaris, and Ochropleura plecta being more abundant in wet/moist habitats and Agrotis exclamationis mostly found at dry sites.
Only two species showed a relationship with management (mowing/grazing) indicators, but these were both strongly positively associated with managed habitats: Agriphila straminella* and Eilema lutarellum*. Noctua comes $^{*}$ was the only species associated (positively) with estimated high local nectar production.

\section{Relationship between general moth abundance, vegetation, and ecological site characteristics}

The number of moth individuals caught per night (moth abundance) was positively correlated with both the number of plant genera $(r=0.35, p=0.050$, Fig. 6$)$ and the number of woody plant genera $(r=0.39, p=0.028$, Fig. 7$)$ in the surrounding vegetation, but not with tree canopy cover $(\mathrm{p}=0.61)$. Among the ecological site characteristics estimated from the mean indicator values of the plant species present, only moisture was significantly (negatively) correlated with moth abundance $(r=-0.39, p=0.027)$ although there was a weak tendency also for higher moth abundance at sites with higher soil $\mathrm{pH}$ $(\mathrm{r}=0.30, \mathrm{p}=0.095)$ and higher estimated nectar production $(r=0.31, p=0.088)$. Estimated shading, soil nutrients, 


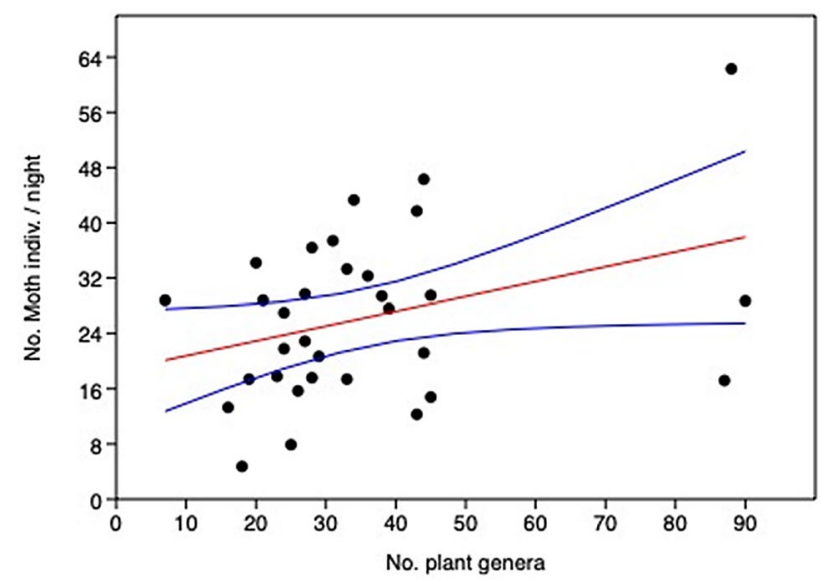

Fig. 6 The relationship between the number of moth individuals caught per night per month (moth abundance) and the number of vascular plant genera found within a radius of $5 \mathrm{~m}$ from the trapping site. The correlation is significant $(p=0.050)$ and the blue lines represent $95 \%$ confidence intervals for the fitted line

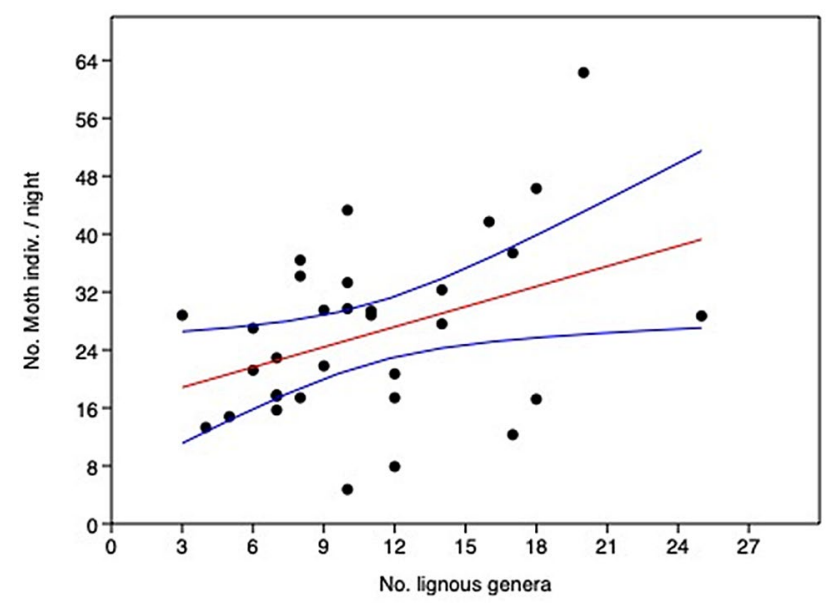

Fig. 7 The relationship between the number of moth individuals caught per night per month (moth abundance) and the number of woody plant genera within sight from the trapping site. The correlation is significant $(p=0.028)$ and the blue lines represent $95 \%$ confidence intervals for the fitted line

management and disturbance showed no relationship with moth abundance $(\mathrm{p}>0.25)$.

\section{Relationship between moth species richness and diversity, vegetation and ecological site characteristics}

The number of moth species caught per night (moth species richness) was positively correlated with the number of woody plant genera in the surroundings $(r=0.37, p=0.039$, Fig. 8), but not with total plant diversity $(\mathrm{p}=0.42)$, nor with tree canopy coverage $(\mathrm{p}=0.24)$. Among the ecological site

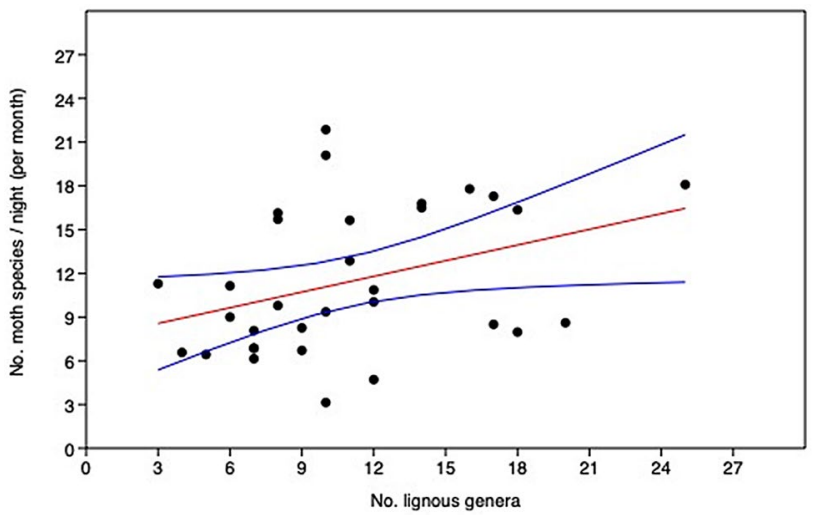

Fig. 8 The relationship between the number of moth species caught per night per month (moth diversity) and the number of woody plant genera within sight from the trapping site. The correlation is significant $(p=0.039)$ and the blue lines represent $95 \%$ confidence intervals for the fitted line

characteristics estimated from the mean indicator values of the plant species present, none were significantly correlated with moth species richness, but there was a tendency for sites with higher nitrogen availability to have higher moth species richness $(r=0.29, \mathrm{p}=0.11)$ whereas all other factors appeared irrelevant $(\mathrm{p}>0.20)$.

The Shannon diversity of the moth communities was not significantly correlated with any of the site characteristics analyzed.

\section{Discussion and conclusions}

In spite of the presumed high mobility of moths, the supposition that the areas important for moth reproduction and larval development may be quite different from those where adult moths find shelter and forage on e.g. nectar (for those doing so as imagos) and the feeling expressed by some moth enthusiasts that any moth species may be observed anywhere provided that enough effort is made, the present study revealed a highly significant general association between vegetation composition, ecological site characteristics and the composition of the moth community (e.g. Figure 4). Similar conclusions have been reached by multiple previous studies (Axmacher et al. 2009; Truxa and Fiedler 2012a; Uhl et al. 2016; Infusino and Scalerico 2018; de Miranda et al. 2019), although mostly in tropical regions and when considering a more restricted range of habitat types. Although there is a lack of empirical data for most species, it is reasonable to assume that the mobility differs much between moth species (Merckx et al. 2009); while the ability of some large species to perform continent-wide migrations is well documented, many microlepidopterans and also some larger species with strict habitat requirements may be assumed to 
only rarely depart from their preferred habitat or host plants (Lintott et al 2014). This proves that it is worthwhile to undertake local moth surveys to provide background information for general conservation planning, as well as when protected areas are planned and before their management is proposed, as also indicated by previous studies (Uhl et al. 2016, Zou et al. 2016). Furthermore, it suggests that many moth enthusiasts that tend to restrict their studies to their private gardens, or to a few already well investigated and easily accessible sites, should be recommended to reconsider their practices if they want to contribute data useful for environmental monitoring and conservation planning.

As shown both by the CCA community analysis (Fig. 4) and the relationships between the relative abundance of individual moth species and the environmental variables, tree canopy cover (light penetration) and soil nutrient status were the most influential of these variables. Many moth species may thus be possible to roughly position along these two major gradients, although the present sample does only provide sufficient data for robust statistical analyses of relatively few of the most common species. Thus, some species appear to prefer open, nutrient-poor habitats (e.g. Achlya flavicornis, Eulithis spp., Hypenodes humidalis), while others were mostly found in open nutrient-rich habitats (e.g. Chrysoteucia culmella, Udea lutealis), wooded nutrientpoor (e.g. Eudonia truncicolella, Ectropis crepuscularia) or wooded nutrient-rich (e.g. Mythimna conigera, Ecliptoptera silaceata) habitats (cf. Fig. 5). In contrast, only two species, i.e. Agriphila straminella which feeds on common pasture/ meadow grasses and Eilema lutarellum feeding on lichens growing on stones in dry and exposed habitats, showed a strong positive association to management, and only Noctua comes was significantly associated with estimated high nectar production.

Still, the environmental site variables here deduced from the vegetation characteristics may not be the ones to which the moths respond to directly. However, these ecological gradients may determine, or be associated with, e.g. the distribution of host plant species, presence of predator species or microclimatic conditions important for the moth species. For example, larvae of the Eulithis spp. feed on Vaccinium spp., which are typical plants of open nutrient-poor habitats. Similarly, several of the moth species indicated to prefer moist, wooded, nutrient poor habitats are reported to have Betula pubescens as a major host plant. However, it is notable that a majority of the Geometridae species, even though reported to feed on host plants preferring open habitats, tend to be most abundant at shaded/wooded and nutrient-poor sites, while species of Noctuidae are more prevalent in open and dry habitats. It may be hypothesized that this apparent pattern may have more to do with the higher capacity of Noctuid imagos to fly in more open, dry and windy habitats than with the habitat preferences of their larval stages.
However, it needs to be stressed that much more data from more numerous sites and representing a more complete range of the major environmental gradients of the region would be needed to establish these relationships with confidence. In addition, the statistical significance of most of the individual moth-environment associations found here was rather weak and they are best regarded as hypotheses for future more targeted studies. Furthermore, the environmental site characteristics used here were deduced from the vegetation composition using species-specific indicator values. In some cases such indirect inference may be advantageous to single-point measurements since the true environmental variables may be prone to strong fluctuations in both time and space, but species-specific indicator values for different environmental/ecological conditions are not equally good at detecting variation in the underlying ecological conditions and the outcome may depend strongly on the ecological context and range of the sites studied. For example, deducing nectar production from vegetation composition may be problematic due e.g. to that flower production may in some cases, and in particular habitats, be decoupled from species presence and survival.

Concerning the question whether or not there is a positive association between the diversity or species richness of different organismal groups at individual sites, the present study suggests that there is indeed a positive relationship between local plant species richness and moth abundance and/or species richness (Figs. 5, 6, 7). Similar results have also been obtained in some previous studies (e.g. Axmacher et al. 2009; Root et al. 2017), but there are also reports of opposite patterns (Axmacher et al 2004). From a theoretical perspective, given that the larval stages of almost all moth species feed on one or a few particular vascular plant taxa, such a relationship should be expected, but the relationship may be compromised by the high mobility of the imagos and the ability of many moth species to feed on more than one host plant. However, compared to the almost sevenfold difference in moth richness and abundance between the richest and poorest sites in this study, the effect sizes of the factors significantly associated with this variation may appear rather small (Figs. 6, 7, 8) and most trends were only barely significant. The fact that only week relationships were observed in the present study may be attributable to the above-mentioned mobility of the moths, but also to the relatively small sample size (32 sites), the difficulty to define an appropriate geographic scale for the habitat descriptors since different moth species are likely to move different distances, and the fact that there may be many other factors that influence the number of moths caught in traps in the field and which are difficult to control for in field-based studies. It is well known that weather conditions (in particular temperature and air humidity of both the same and previous nights) have a strong influence on moth activity (Jonason et al. 2014), 
but also e.g. shading from competing light sources (both anthropogenic and natural such as moonshine and stars) and microtopographic conditions may be significant for the results. Microtopography and shading may also influence the microclimatic conditions, but the fact that no significant effects of tree canopy cover was observed here suggests that this factor have not had a strong influence on the results and conclusions. It may thus be speculated that the true association and effect sizes between moth and vegetation diversity may be much stronger/higher than observable in field studies like the one presented here, but data from more sites and gathered in a more structured way, though difficult to achieve due to logistic constraints, will be needed to show this.

While estimated moth species richness and abundance were found to be correlated with vegetation and other site characteristics, no correlations with Shannon diversity were found. Apparently, this was because the most species-rich local moth assemblages at the same were strongly dominated by a few common species with very high abundance, reducing evenness and Shannon diversity.

Concerning any associations between moth diversity and abundance and other ecological site characteristics, the results of the present analyses, although only partly statistically significant, seems to suggest that both the diversity and abundance of moths is higher at sites with more productive soils and vegetation (i.e. higher $\mathrm{pH}$ and moisture and nutrient availability). This conclusion may be enforced by simply looking at photos of the sites were most and least moths were caught (Figs. 2, 3). In general, the highest numbers of both moth species and individuals were caught in highly productive deciduous forests, followed by gardens and parks and wooded and open seminatural grasslands, while the lowest numbers were caught in coniferous forests, clear-cuts, bogs, wetlands and heath-like sites. It may appear intuitive that higher plant biomass and productivity may support a richer moth community, but on the other hand are more productive plant communities commonly less diverse/species rich than less productive ones and fertilization tends to reduce plant species richness. The results also suggest a higher moth richness and abundance in wooded sites than in open grasslands, as previously also found by e.g. Merckx et al. (2012, 2019).

However, the results of the present study may have been compromised by the extremely broad ecological range of the study sites making it difficult to detect relationships with individual environmental parameters, in particular given the relatively low number of sites possible to sample with available resources. Thus, future studies with an approach similar to the one presented here, but focussing on a more narrow and well-defined range of habitats (i.e. particular forest types or seminatural grasslands of different ages or managements, cf. Littlewood 2008; Moon et al. 2018) should be encouraged and may prove more conclusive.
Still, it may be concluded from the present study that local moth communities as represented by light-trap catches do indeed vary with local habitat characteristics and at least some of this variation is clearly related to vegetation characteristics or ecological drivers simultaneously affecting both the vegetation and the moth community. Today, moths are only very rarely considered in conservation contexts (New 2004; Ballesteros-Mejia et al. 2017) and in particular so in the Nordic region. The reason may be a combination of a general ignorance concerning moths and a belief that moths are very difficult and resource consuming to survey. However, the results of the present study suggest that obtaining valuable moth data may not need to be very cumbersome although repeated trapping during all or most months of the season may be needed (Summerville and Crist 2003).

Acknowledgements My thanks are due to all members of the Facebook community 'Nattfärilarnas Vänner', in particular Pål Axel Olsson, Hans Petersson and Kim Rossi, without the help from which many moths found in this study would have remained unidentified, and to Stefan Lemurell, responsible for the extremely pedagogic and useful web resource 'Vilken Art' without which a botanist and plant ecologist like me would probably never had been able enter to the world of moths. I am further indebted to my son, Ture Birkedal, who let me put out and empty all these traps on our way to and back from kindergarden.

Funding Open access funding provided by Lund University.

\section{Compliance with ethical standards}

Conflict of interest The author has no conflict of interest to declare with respect to this research.

Ethical approval All animals caught at night for the study were released the following morning after having been photographed. All catches were made in compliance with Swedish law and regulations; no special permissions were needed to catch and release moths at the study sites. The work was financed solely by the author.

Open Access This article is licensed under a Creative Commons Attribution 4.0 International License, which permits use, sharing, adaptation, distribution and reproduction in any medium or format, as long as you give appropriate credit to the original author(s) and the source, provide a link to the Creative Commons licence, and indicate if changes were made. The images or other third party material in this article are included in the article's Creative Commons licence, unless indicated otherwise in a credit line to the material. If material is not included in the article's Creative Commons licence and your intended use is not permitted by statutory regulation or exceeds the permitted use, you will need to obtain permission directly from the copyright holder. To view a copy of this licence, visit http://creativecommons.org/licenses/by/4.0/.

\section{References}

Axmacher JC, Tunte H, Schrumpf M, Müller-Hohenstein K, Lyaruu HVM, Fiedler K (2004) Diverging diversity patterns of vascular plants and geometrid moths during forest regeneration on $\mathrm{Mt}$ 
Kilimanjaro, Tanzania. J Biogeogr 31:895-904. https://doi.org/1 0.1111/j.1365-2699.2004.00995.x

Axmacher JC, Brehm G, Hemp A, Tunte H, Lyaruu HVM, MüllerHohenstein K, Fiedler K (2009) Determinants of diversity in afrotropical herbivorous insects (Lepidoptera: Geometridae): plant diversity, vegetation structure or abiotic factors? J Biogeogr 36:337-349. https://doi.org/10.1111/j.1365-2699.2008.01997.x

Ballesteros-Mejia L, Kitching IJ, Jetz W, Beck J (2017) Putting insects on the map: near-global variation in sphignid moth richness along spatial and environmental gradients. Ecography 40:698-708. https ://doi.org/10.1111/ecog.02438

Beck J, Brehm G, Fiedler K (2011) Links between the environment, abundance and diversity of Andean moths. Biotropica 43:208217. https://doi.org/10.1111/j.1744-7429.2010.00689.x

Brunbjerg AK, Bruun HH, Dalby L, Fløjgaard C, Frøslev TG, Høye TT, Goldberg I, Læssøe T, Hansen MDD, Brøndum L, Skipper L, Fog K, Ejrnæs R (2018) Vascular plant species richness and bioindication predict multi-taxon species richness. Methods Ecol Evol 2018:2372-2383. https://doi.org/10.1111/2041-210X.13087

De Miranda MD, Pereira HM, Corley MFV, Merckx T (2019) Beta diversity patterns reveal positive effects of farmland abandonment on moth communities. Sci Rep 9:1549. https://doi.org/10.1038/ s41598-018-38200-3

Fiedler K, Truxa C (2012) Species richness measures fail in resolving diversity patterns of speciose forest moth assemblages. Biodivers Conserv 21:2499-2508. https://doi.org/10.1007/s1053 1-012-0311-5

Franzén M, Johannesson M (2007) Predicting extinction risk of butterflies and moths (Macrolepidoptera) from distribution patterns and species characteristics. J Insect Conserv 11:367-390

Gaston KJ (1996) Biodiversity-congruence. Prog Phys Geogr 20:105-112

Groenendijk D, Ellis WN (2011) The state of the Dutch larger moth fauna. J Insect Conserv 15:95-101

Hammer $\varnothing$, Harper DAT, Ryan PD (2001) PAST: Paleontological Statistics software package for education and data analyses. Paleontol Electron 4(1):1-9

Highland SA, Miller JC, Jones JA (2013) Determinants of moth diversity and community in a temperate mountain landscape: vegetation, topography, and seasonality. Ecosphere. https://doi. org/10.1890/ES12-00384.1

Horvath B, Toth V, Lakatos F (2016) Relation between canopy-layer traits and moth communities in sessile oak-hornbeam forests. North-west J Zool 12:213-219

Infusino M, Scalerico S (2018) The importance of beech forests as reservoirs of moth diversity in the Mediterranean basin. Fragm Entomol 50:161-169. https://doi.org/10.4081/fe.2018.294

Jonason D, Franzén M, Ranius T (2014) Surveying moths using light traps: effects of weather and time of year. PLoS ONE 9:e92453

Lintott PR, Brunnefeld N, Fuentes-Montemayor E, Minderman J, Blackmore L, Goulson D, Park KJ (2014) Moth species richness, abundance and diversity in fragmented urban woodlands: implications for conservation and management strategies. Biodivers Conserv 23:2875-2901

Littlewood NA (2008) Grazing impacts on moth diversity and abundance on a Scottish upland estate. Insect Conserv Divers $1: 151-160$

Merckx T, Slade EM (2014) Macro-moth families differ in their attraction to light: implications for light-trap monitoring programmes. Insect Conserv Divers 7:453-461. https://doi.org/10.1111/ icad. 12068
Merckx T, Feber RE, Dylieu RL, Townsend MC, Parsons MS (2009) Effects of field margins on moths depends on species mobility: field-based evidence for landscape-scale conservation. Agr Ecosyst Environ 129:302-309

Merckx T, Marini L, Feber RE, Macdonald DW (2012) Hedgerow trees and extended-width field margins enhance macro-moth diversity: implications for management. J Appl Ecol 49:1396-1404. https:// doi.org/10.1111/j.1365-2664.2012.02211.x

Merckx T, de Miranda MD, Pereira HM (2019) Habitat amount, not patch size and isolation, drives species richness of macro-moth communities in countryside landscapes. J Biogeogr 46:56-967. https://doi.org/10.1111/jbi.13544

Moon MY, Kim SS, Lee DS, Yang HM, Oark CW, Kim HS, Park Y-S (2018) Effects of forest management practices on moth communities in Japanese Larch (Larix kaempferi (Lamb.) Carriere) plantations. Forests 9:574. https://doi.org/10.3390/f9090574

New TR (2004) Moths (Insecta: Lepidoptera) and conservation: background and perspective. J Insect Conserv 8:79-94

Rodrigues AS, Brooks TM (2007) Shortcuts for biodiversity conservation planning: the effectiveness of surrogates. Annu Rev Ecol Evol Syst 38:713-737

Root HT, Verschuyl J, Stokely T, Hammond P, Scherr MA, Betts MG (2017) Plant diversity enhances moth diversity in an intensive forest management experiment. Ecol Appl 27:134-142

Sorg M, Schwan H, Stenmans W, Müller A (2013) Ermittlung der Biomassen flugaktiver Insekten im Naturschutzgebiet Orbroicher Bruch mit Malaise Fallen in den Jahren 1989 und 2013. Mitteilungen aus dem Entomologischen Verein Krefeld 1:1-5

Summerville KS, Crist TO (2003) Determinants of lepidopteran community composition and species diversity in eastern deciduous forests: roles of season, eco-region and patch size. Oikos 100:134-148

Truxa C, Fiedler K (2012a) Down in the flood? How moth communities are shaped in temperate foodplain forests. Insect Conserv Divers 5:389-397. https://doi.org/10.1111/j.1752-4598.2011.00177.x

Truxa C, Fiedler K (2012b) Attraction to light-from how far do moths (Lepidoptera) return to weak artificial sources of light? Eur J Entomol 109:77-84. https://doi.org/10.14411/eje.2012.010

Tyler T, Herbertsson L, Olsson PA, Fröberg L, Olsson K-A, Svensson $\AA$, Olsson O (2018) Climate warming and land-use changes drive broad-scale floristic changes in Southern Sweden. Glob Change Biol 24:2607-2621. https://doi.org/10.1111/gcb.14031

Tyler T, Herbertsson L, Olofsson J, Olsson PA (2020) Ecological indicator and trait values for Swedish vascular plants. Ecol Indic 106923

Uhl B, Wölfing M, Fiala B, Fiedler K (2016) Micro-moth communities mirror environmental stress gradients within a Mediterranean nature reserve. Basic Appl Ecol 17:273-281. https://doi. org/10.1016/j.baae.2015.10.002

Vaughan N (1997) The diets of British bats (Chiroptera). Mammal Revue 27:77-94

Zou Y, Sang WG, Warren-Thomas E, Axmacher JC (2016) Geometrid moth assemblages reflect high conservation value of naturally regenerated secondary forests in temperate China. For Ecol Manag 374:111-118

Publisher's Note Springer Nature remains neutral with regard to jurisdictional claims in published maps and institutional affiliations. 